\title{
Acupuncture treatment of vasomotor symptoms in men with prostatic carcinoma: A pilot study
}

\author{
Mats Hammar, Jessica Frisk, Ö Grimsås, M Höök, Anna-Clara Spetz and Yvonne Wyon
}

\section{Linköping University Post Print}

N.B.: When citing this work, cite the original article.

Original Publication:

Mats Hammar, Jessica Frisk, Ö Grimsås, M Höök, Anna-Clara Spetz and Yvonne Wyon, Acupuncture treatment of vasomotor symptoms in men with prostatic carcinoma: A pilot study, 1999, Journal of Urology, (161), 3, 853-856.

http://dx.doi.org/10.1016/S0022-5347(01)61789-0

Copyright: Elsevier

http://www.elsevier.com/

Postprint available at: Linköping University Electronic Press

http://urn.kb.se/resolve?urn=urn:nbn:se:liu:diva-25941 


\section{Acupuncture treatment of vasomotor symptoms in men with prostatic carcinoma - a pilot study.}

by

Hammar, M, Frisk J, Grimås Ö, Höök, M reg physiotherapist, Spetz A-C, Wyon Y

Department of Health and Environment; Obstetrics and Gynecology, Faculty of Health Sciences, University of Linköping, S-581 85 Linköping, and *Department of Surgery, County Hospital, Ludvika, Sweden.

Correspondence to: Mats Hammar MD, PhD, Department of Health and Environment; Obstetrics and Gynecology, Faculty of Health Sciences, University of Linköping, S-581 85 Linköping, SWEDEN, tel +46-13-223131, fax +46-13-148156, e-mail: matha@gyn.liu.se

Short title: Acupuncture treatment in men with hot flushes.

Key words: vasomotor symptoms, men, prostatic carcinoma, castration, acupunture 


\begin{abstract}
: (235 words)
Background: Most men who undergo castration therapy due to prostatic carcinoma will suffer from vasomotor symptoms, which usually persist for years. Vasomotor symptoms are elicited from the thermoregulatory center, possibly due to a decrease in hypothalamic opioid activity induced by low sex steroid concentrations. In women acupuncture treatment, which stimulates hypothalamic opioid activity, has been found to alleviate vasomotor symptoms.
\end{abstract}

Material and methods: Seven men, who sufferred from vasomotor symptoms due to castration therapy were invited to have acupuncture treatment 30 minutes twice weekly for two weeks and once a week over another 10 weeks. Effects on the flushes were followed by means of logbooks. Results: Six of the seven men completed at least 10 weeks of the acupuncture therapy, all with a substantial decrease in number of hot flushes. On average they had an almost $70 \%$ reduction of the number of flushes per week and still three months after the last treatment the number of flushes was about 50\% reduced. Two men abandoned therapy due to medical reasons; one had a femoral neck fracture after 10 weeks of therapy and the other man had so severe back pain that he was unable to lie down, for the time needed for acupucture treatment, and left the study already during the third week.

Conclusion: Acupuncture therapy may be a therapeutic alternative in men with hot flushes after castration therapy and merits further evaluation. 


\section{Introduction}

Vasomotor symptoms, including hot flushes and sweating, occur in about three out of four women around menopause and are a consequence of falling sex hormone levels (1-5). They may also be induced in men by current therapies for advanced carcinoma of the prostate, such as bilateral orchidectomy or medical castration with gonadotropin releasing hormone $(\mathrm{GnRH})$ analogues. This distressing condition has received little attention in the urological literature, possibly because hot flushes are thought to be self limiting.

In 1896 Cabot studied the effect of castration for treatment of enlargement of the prostate and reported "uncomfortable flushes of heat, similar to those experienced by women at the time of the menopause" (6). In the thirties McCullagh and Renshaw reported that, after castration, seven out of twelve men complained of sudden flushing and sensations of heat or chilling. "The hot flushes occured as many as four or five times daily for a period of several years and tended gradually to decrease in number and severity"(7). Huggins and Hodges found that nine out of 21 orchidectomized patients reported episodic hot flushes and perspiration, beginning two to six weeks after the operation (8). Ginsburg and O'Reilly reported hand blood-flow during a hot flush 
attack after orchidectomy (9) and changes in skin blood-flow and water evaporation were found in 13 postorchidectomy patients during flushing (10). Reports emphasize that hot flushes are sometimes the most distressing symtom, and were reported after orchidectomy in $58-76 \%$ of the cases $(10,11)$, in which $27 \%$ were greatly distressed $(10)$. With GnRH analogue treatment 76$77 \%$ of the patients had flushes $(12,13)$.

Frequent flushes affect the quality of life profoundly and are experienced by up to $85 \%$ of women $(1,2,14,15)$. Some women have sleep disturbances due to their vasomotor complaints, which can lead to fatigue and irritability $(1,2,15)$.

In postmenopausal women the vasomotor symptoms often disappear after 2 to 5 years but may persist for up to more than 10-15 years $(2,3)$, Also in men it has been found that the symptoms usually persist for more than 5 years (16).

A sudden downward shift of the set point of the hypothalamic thermoregulatory center is believed to induce the flushes $(1,4,17-19)$. This is supported by observations during the flush of increased peripheral blood flow, pulse rate, skin conductance and in skin temperature (18-21) with a fall in body core temperature $(1,2,14,18)$. These phenomena lead to or are signs of heat loss. The flushes are sometimes followed by chills or shivering if significant heat loss has occured $(2,18)$. The cause of the alterations in the thermoregulatory center is still unknown. An altered autonomic activity probably cause the increased blood flow (20). Increased circulating epinephrine during a flush is consistent with the increase in heart rate, and a lower concentration of norepinephrine is consistent with the augmented blood flow, since the circulation through the skin of the hands is under $\alpha$-adrenergic vasoconstrictor control $(18,20)$. Also the increased blood-flow may be induced by the potent vasodilatory neuropeptide calcitonin gene-related peptide (CGRP), which has been suggested to be involved in vasomotor symptoms in women around menopause $(22,23)$. The exact role of estrogen in the etiology of hot flushes in women is not clear. Some studies have reported that circulating levels of estrogen are lower in women with flushes than in women without flushes $(24,25)$ but other studies found no such correlation $(21,26)$.

Possibly hypothalamic factors associated with the release of GnRH are involved in vasomotor symptom genesis $(14,19,27,28)$. The flushes characteristically coincide with peaks in LH and GnRH secretion $(14,18,21,27-29)$. A hypothetical model of the genesis of hot flushes presented by Lomax (14) is based on the fact that noradrenergic (NA) neurons and pacemaker neurons 
stimulate hypothalamic GnRH-release. The negative feedback of estradiol might be mediated by ß-endorphin induced inhibition of the NA pathways; ovarian failure leads to a decrease in hypothalamic $\beta$-endorphin activity and disinhibition of the NA drive and increased GnRH release. The GnRH neurons are located close to the thermoregulatory center and the enhanced activity in the hypothalamus could lead to a transient fall in the thermoregulatory set point, thus triggering the hot flush (14). Also, opioids have direct effects on thermoregulation and possibly a decrease in hypothalamic $\beta$-endorphin activity makes thermoregulation less stable (30). In women treatments which affect hypothalamic $\beta$-endorphin activity, like estrogen therapy, physical exercise or acupuncture are associated with a lower prevalence of vasomotor symptoms $(14,23,31,32)$. Menopausal women with hot flushes are usually treated with hormone replacement therapy (HRT), which is almost always successfull. Some women, however, do not want such therapy or are prevented from HRT due to relative or absolute contraindications. There are rather few non-pharmacological alternatives to HRT but behavioral therapy and acupuncture have been suggested $(23,33,34)$. Acupuncture therapy increases hypothalamic $\beta$-endorphin activity and was found to decrease the frequency of hot flushes in postmenopausal women (23). In men with hot flushes treatment with diethylstilbestrol or megestrol acetate reduces the flushes effectively, whereas non-hormonal therapies are less effective $(35,36)$. No studies of alternative therapies have been reported in men with vasomotor symptoms, although there is a need for alternatives. The aim of this study was to establish whether acupuncture therapy could be used as treatment for vasomotor symptoms in men who had castration therapy due to prostatic carcinoma.

\section{Material and methods:}

Seven men who sufferred from vasomotor symptoms due to castration therapy were invited to take part in the pilot study. They all attended the outpatient clinic at the department of surgery at the county Hospital of Ludvika, Sweden and reported vasomotor symptoms. Data on the men are summerized in Table 1. After oral and written information they gave consent to take part in the study of acupuncture therapy 30 minutes twice a week during two weeks and thereafter once a week during 10 weeks. The mode of acupuncture therapy was the same as that being used in a current, own study of acupuncture therapy for women with vasomotor symptoms and breast cancer and in turn a slight modification of a published model by the same authors (23). The 
acupuncture points used are shown in Table 2 and a $2 \mathrm{~Hz}$ current was used at BL23 and BL 32. Acupuncture was given by a physiotherapist $(\mathrm{MH})$ who is also one of the authors.

Effects on the flushes were followed by means of logbooks that the men were asked to fill in during one week before therapy and thereafter during one week after 2, 6 and 10 weeks of therapy and three months after end of therapy (week 24). They were asked to daily fill in the total number of flushes experienced during the last day and the last night.

Statistics: The number of flushes per week were calcualted for each man and thereafter handled with Statview 4.1. Nonparametrical methods were used for descriptive and comparative purposes. Ethics: Acupuncture therapy for women and men with vasomotor symptoms had been approved by the Ethical Committee at the Faculty of Health Sciences, University of Linköping.

\section{Results:}

Six of the seven men completed at least ten weeks of the acupuncture therapy, all with a substantial decrease in number of hot flushes (Table 3, Figure 1). Data from these six men were used for statistical analysis.

Two men abandoned therapy due to medical reasons; one had a femoral neck fracture after 10 weeks of acupuncture therapy (patient No 6) and the other (patient No 7) had so severe back pain that he was unable to lie down for the time needed for acupuncture therapy. Therefore he abandoned therapy already during the third week of therpay. A third man (patient No 5) had such a long distance to travel for every acupuncture treatment, and was so content with the treatment effects after 10 weeks of therapy, that he decided to abandon the last two treatments. His number of flushes had decreased from 5-7/day before therapy to 1-2/day during the 10th week. Pairwise comparison of the number of flushes/week before therpy with the numbers reported during therapy showed a statistically significant decrease after 6, 10 and 24 weeks $(p<0.05)$. With the use of One Factor ANOVA-repeated measures there was also a statistically significant decrease in number of flushes with time and treatments $(\mathrm{P}=0.0037)$. This significance was confirmed with the nonparametrical Friedman's test $(\mathrm{P}=0.0065)$.

\section{Conclusion:}


Vasomotor symptoms with hot flushes and sweating are common in men with prostatic carcinoma and castration therapy $(9,10)$. There are some endocrine therapies available but when hormone therapies are not wanted there are few alternatives $(35,36)$. In this small nonrandomized, pilot study we found that electrosimulated acupuncture therapy may be a therapeutic alternative in men with hot flushes after castration therapy and should be further evaluated. Of course there is a need for larger randomized studies using a control group and also some kind of placebo therapy, in order to evaluate acupuncture therapy in men. However, a reduction in number of flushes with more than 50\% during therapy, as seen in the present study, has not been previously reported in placebo groups concerning hot flushes in women or men (34,35). Actually Freedman and coworkers reported almost no placebo effect in a number of women with hot flushes treated with behavioral therapy (34).

In the present study men, who received 10-12 weeks of treatment with electrostimulated acupuncture once to twice a week for 30 minutes each time, had a decrease in number of vasomotor attacks with more than 50\% persisting for at least 3 months after the end of treatment. Such a treatment effect is greater than that reported by Freedman and Woodward after behavioral treatment of hot flushes in women with paced respiration (34) and similar to that reported by ourselves after acupuncture therapy of women with hot flushes (23).

Today the treatment of choice for climacteric women suffering from vasomotor symptoms is without doubt estrogen replacement therapy. As mentioned previously the main reason for the vasomotor symptoms is still not known with certainty. Lability in the thermoregulatory centre appears to be the cause but the reason for this is unknown. Changes in hypothalamic neurotransmittor activity, such as ß-endorphin, noradrenalin or catechol estrogens, have been suggested $(2,14,17,18,21)$.

Regular physical activity and acupuncture have been shown to affect hypothalamic $\beta$-endorphin activity and may on these grounds be beneficial for vasomotor symptoms. Postmenopausal women taking part in regular physical exercise have been found to suffer less from vasomotor symptoms than control women (31) and there was a significant reduction in menopausal hot flushes in women treated with acupuncture for 8 weeks with persistant reduction still three 
months after end of therapy in those women, who had received electrostimulated acupuncture (23).

The use of logbooks, with daily recordings of the number and intensity of hot flushes and sweating during the last 24 hours, appears to be a good way to monitor the vasomotor symptoms. According to a previous study (23) the most valid way of monitoring such symptoms seems to be to measure the total number of flushes during day and night and no further information was obtained when flushes were counted separately during day and night respectively or when the flushes were not only counted but also weighted according to severity per day or night or during 24 hours. In the present study, therefore, the men were asked only to count the total number of flushes per 24 hours and note in the logbook.

Scientific evaluation of acupuncture has mostly concerned treatment of pain and to our knowledge there are no previously reported scientific studies on acupuncture treatment of vasomotor symptoms in men. There are certain problems in evaluating acupuncture and most trials have been considered poor $(37,38)$. Some studies have been difficult to evaluate due to a variable number of treatment sessions for different patients (39), something that we avoided through a project plan including a fixed number of treatments, although that plan could not be followed in all men.

Studies have usually been uncontrolled and, as is the case for no-treatment controlled trials, give little or no information concerning specific as opposed to non-specific factors responsible for the effectivity of treatment (39). Generally, acupuncture might well be expected to have a powerful non-specific placebo effect considering that it is a form of therapy with an aura of mysticism and has been used successfully in the Far East (cf 39). Therefore, it may be difficult to assess whether it has specific effects beyond this, and it is a great need for a suitable needle "control" treatment, which we have not yet found. Placebo-controlled trials have been made with acupuncture at correct versus incorrect points ("sham-acupuncture"). A few such studies have shown significant differences between classical and "sham" acupuncture, whereas most studies have included too few patients to enable statistical comparisons (39). 
In the present study, the choice of acupuncture points was based on previous experience from a study of acupuncture treatment in primary dysmenorrhea (40) and in women with hot flushes (23). In those studies stimulation of the same acupuncture points were found effective, probably at least partially through general effects on $\beta$-endorphin production. Lack of previous scientific reports on acupuncture treatment of hot flushes in men, however, made it impossible to consider certain points as correct and others as "sham".

Electrostimulated acupuncture (EA) and transcutaneous electrical stimulation have previously been compared to manual stimualtion and for a long time these studies have shown somewhat inconclusive results $(41,42)$. When classical acupuncture in later studies was used for treatment of chronic pain, it was found to have more marked effects than superficial needle insertion (43) and low frequency $(2 \mathrm{~Hz})$ EA to induce a more sustained effect when compared to high frequency $(80 \mathrm{~Hz})$ EA or "classical" acupuncture (44). When we compared superficial needle insertion and low frequency $(2 \mathrm{~Hz})$ EA in menopausal women (23), EA appeared to have more longstanding effects than than superficial needle insertion. In the present study of vasomotor symptoms in men we did not compare superficial needle insertion with EA. Of course the promising results obtained in the present study merit a randomized, controlled study including for example a comparison between superficial needle insertion and low frequency $(2 \mathrm{~Hz})$ EA. They aim should be to identify the specific effects from acupuncture and ideally to be able to separate specific effects from non-specific placebo effects. It should be emphasized, however, that placebo treatment as such has been suggested to induce $\beta$-endorphin release, based on the fact that placebo-induced pain relief could be blocked by naloxone (45). If endorphins are involved in the vasomotor symptoms it may explain why the vasomotor symptoms decrease during placebo treatment as well as during superficial needle insertion acupuncture treatment (23). The longstanding effects for at least 3 months, however, suggest something more than only placebo effects.

In a study by Freedman and Woodward (36) control groups receiving muscle relaxation and alpha-wave feedback did not decrease their number of flushes per day whereas the "active" treatment with paced respiration decreased the number of flushes to about $50 \%$ of pre-treatment 
level. In relation to those results, the decrease in number of flushes with more than $50 \%$ induced by acupuncture in our study, does not seem to be a placebo effect.

A cross-over design may seem attractive, but the fact that the acupuncture effects persisted for at least three months in our current and previous study (23), would make it necessary to use a washout period of more than 3 months. Such a long wash-out period would probably be difficult to prescribe.

Acupuncture and transcutaneous electrical stimulation have been shown to increase the threshold for pain and to affect central neuronal activity $(43,46)$. The acupuncture points used in the present study are thought to have general effects on patients with pain (40). It is reasonable, however, that other points, and different treatment duration and intervals could be more efficient when treating postmenopausal women with vasomotor symptoms. It must also be emphasized that we do not yet know with certainty that acupuncture induced anything but a placebo effect, as we have not been able to perform a controlled study with two different regimens of acupuncture or with acupuncture and another non-pharmacological or pharmacological therapy.

In the etiology of climacteric vasomotor symptoms, disturbances of the regulatory role of opioids have been suggested. It is possible that changed hormonal levels result in sensitization of peripheral and central neurons making them more susceptible to neural input, which may to some extent explain the vasomotor symptoms seen in the perimenopause. In a former study, we found higher levels of CGRP-like immunoactivity in 24 hour urine before acupuncture treatment than in the same women after successful acupuncture therapy (23). This is interesting to note as CGRP produces vasodilation and hot flushes when administered intravenously in healthy young men (47). The significant decrease of CGRP seen after acupuncture in that study (23) could explain the reduction of symptoms reported. The reduction in concentrations of CGRP may be attributed to the fact that the central opioids seem to inhibit the release of CGRP (48).

In conclusion six men with vasomotor symptoms after castration therapy had significant effects of 10 to 12 weeks of acupuncture treatment with decreasing frequency of hot flushes registered in the logbooks. Acupuncture appears to be an interesting method for further studies aimed at increasing the armamentarium for treatment of men with vasomotor symptoms. 
Acknowledgements: We are thankful to Vårdalstiftelsen, The Swedish Medical Research Council grant no K98-17X-12651-01A and Cancer och Trafikskadades Förbund for financial support.

\section{References}

1. Rebar R.W. and Spitzer I.B: The physiology and measurement of hot flushes. Am. J. Obstet Gynecol 1987; 156: 1284-1288.

2. Kronenberg, F.: Hot flashes: Epidemology and Physiology. Annals New York Academy of Sciences. 592: 52-86, 1990.

3. Berg G, Gottvall T, Hammar M, Lindgren R. Climacteric symptoms among women aged 60-62 in Linköping, Sweden, in 1986. Maturitas 1988; 10: 193-199.

4. Hammar M, Berg G, Fåhraeus L, Larsson-Cohn U. Climacteric symptoms in an unselected sample of Swedish women. Maturitas 1984; 6: 345-350.

5. Jaszmann LJ B. Epidemiology of the climacteric syndrome. In: Campbell S, ed. The management of the menopause and postmenopausal years. Lancaster: MTP Press, 1976; 11-23.

6. Cabot, A. T.: The question of castration for enlarged prostate. Am Surg, 24:265, 1896.

7. McCullagh, E. P. and Renshaw, M. D.: The effects of castration in the adult male. JAMA, $1140,1934$.

8. Huggins, C., Stevens, R. E. and Hodges, C. V.: Studies on prostatic cancer: II. The effects of castration on advanced carcinoma of the prostate gland. Arch. Surg., 43: 209, 1941. 
9. Ginsburg, J. and O’Reilly, B.: Short reports: Climacteric flushing in man. Brit. Med. J., 287:262, 1983.

10. Frödin, T., Ålund, G. and Varenhorst, E.: Measurement of skin blood-flow and water evaporation as a means of objectively assessing hot flushes after orchidectomy in patients with prostatic cancer. The Prostate, 7: 203, 1985.

11. Charig, C. R. and Rundle, J. S.: Flushing: Long-term side effect of orchiectomi in treatment of prostatic carcinoma. Urology, 33/3: 175, 1989.

12. Parmar, H., Edwards, L., Phillips, R. H., Allen, L. and Lightman, S. L.: Orchiectomy versus long acting D-trp-6-LHRH in advanced prostatic cancer. Brit. J. Urol., 59: 248, 1987.

13. Smith, J. A.: Androgen suppression by a gonadotropin releasing hormone analogue in patients with metastatic carcinoma of the prostate. J. Urol., 131: 1110, 1984.

14.Lomax P, Schönbaum E. Postmenopausal hot flushes and their management. Pharmac Ther 1993; 57: 347-358.

15. Oldenhave A, Jaszmann LJB, Haspels AA, Everaerd WTAM. Impact of climacteric on wellbeing. A survey based on 5213 women 39 to 60 years old. Am J Obstet Gynecol 1993; 168: 772780.

16 Karling P, Hammar M, Varenhorst E. Prevalence and duration of vasomotor symptoms after surgical or medical castration in men with prostatic carcinoma. J Urology, 1994; 152; 1170-1173.

17. Tataryn IV, Lomax P, Bajorek JG, Chesarek W, Meldrum DR, Judd HL. Postmenopausal hot flushes: a disorder of thermoregulation. Maturitas 1980; 2: 101-107. 
18. Kronenberg F, Cote LJ, Linkie DM, Dyrenfurth I, Downey JA. Menopausal hot flashes: thermoregulatory, cardiovascular, and circulating cathecholamine and LH changes. Maturitas 1984; 6: 31-43.

19. Tataryn IV, Lomax P, Meldrum DR, Bajorek JG, Chesarek W, Judd HL. Objective techniques for the assessment of postmenopausal hot flashes. Obstet Gynecol 1981; 57: 340-344.

20. Ginsburg J, Swinhoe J, O'Reilly B. Cardiovascular responses during the menopausal hot flush. Br J Obstet Gynecol 1981; 88: 925-930.

21. Meldrum DR, Tataryn IV, Frumar AM, Erlik Y, Lu KH, Judd HL. Gonado-tropins, estrogens, and adrenal steroids during the menopausal hot flash.Clin Endocrin Metab 1980; 50: 685-689.

22. Chen J-T, Hirai Y, Seimiya Y, Hasumi K, Shiraki M. Menopausal flushes and calcitoningene-related peptide. Lancet 1993; 342: 49.

23. Wyon Y, Lindgren R, Lundeberg T, Hammar M. Effects of acupuncture on climacteric vasomotor symptoms, quality of life, and urinary excretion of neuropeptides among postmenopausal women. Menopause 1995; 2: 3-12.

24. Erlik Y, Meldrum DR, Judd HL. Estrogen levels in postmenopausal women with hot flashes. Obstet Gynecol 1982; 59: 403-407.

25. Hagen C, Christiansen C, Christensen MS, Transboel I. Climacteric symptoms, fat mass, and plasma concentrations of LH, FSH, Prl, oestradiol-17 and androstenedione in the early postmenopausal period. Acta Endocrin 1982; 101: 87-92.

26. Hutton JD, Jacobs HS, Murray MAF, James VHT. Relation between plasma oestrone and oestradiol and climacteric symptoms. Lancet 1978; 678-681. 
27. Tataryn IV, Meldrum DR, Lu KH, Frumar AM, Judd HL. LH, FSH and skin temperature during the menopausal hot flash. J Clin Endocrin Metab 1979; 49: 152-154.

28. Casper RF, Yen SSC, Wilkes MM. Menopausal flushes: a neuroendocrine link with pulsatile luteinizing hormone secretion. Science 1979; 205: 823-825.

29. Meldrum DR, Defazio JD, Erlik Y, Lu JKH, Wolfsen AF, Carlson HE, Hershman JM, Judd HL. Pituitary hormones during the menopausal hot flash. Obstet Gynecol 1984; 64: 752-756.

30. Cagnacci A, Melis GB, Soldani R, Paoletti AM, Fioretti P. Effect of sex steroids on body temperature in postmenopausal women. Role of endogenous opioids. Life Sci 1992; 50: 515-520.

31. Hammar, M, Berg G, Lindgren R. Does physical exercise influence the frequency of postmenopausal hot flushes? Acta Obstet Gynecol Scand 1990; 69: 409-412.

32.Wardlaw SL, Wehrenberg WB, Ferin M, Antunes JL, Frantz AG. Effect of sex steroids on endorphin in hypophyseal portal blood. J Clin Endocrin Metab 1982; 55: 877-881.

33. Wijma K, Melin A, Nedstrand E, Hammar M. Treatment of menopausal symptoms with applied relaxation: a pilot study. J Behav Ther Exp Psychiat. 1997; 28: 251-261.

34. Freedman RR, Woodward S. Behavioral treatment of menopausal hot flushes: evaluation by ambulatory monitoring. Am J Obstet Gynecol 1992; 167: 436-439.

35. Atala, A., Amin, M, Harty, J. I. Diethylstilbestrol in treatment of postorchiectomy vasomotor symptoms and its relationship with serum follicle-stimulating hormone, luteinizing hormone, and testosterone. Urology, 39: 108-110, 1992. 
36 Smith A. A prospective comparison of treatments for symptomatic hot flushes following endocrine therapy for carcinoma of the prostate. J Urol. 1994; 152: 132-34.

Kvar:14. Kolla grad av placeboeffekt!: Eaton, A. C. and McGuire, N.: Cyproterone acetate in treatment of postorchidetomy hot flushes. Double-blind cross-over trial. Lancet, 10: 1336, 1983.

37. Levith GT. Can we assess the effects of acupuncture? BMJ 1984; 288: 1475-1476.

38. Ter Reit G, Kleijnen J, Knipschild P. Acupuncture and chronic pain: A criteria-based metaanalysis. J Clin Epidemiol 1990; 43 (II): 1191-1199.

39. Baldry PE Scientific evaluation of acupuncture. In: Acupuncture, trigger points and musculoskeletal pain. Churchill Livingstone, Edinburgh, London, 1993;125-138.

40. Thomas M, Lundeberg T, Björk G, Lundström-Lindstedt V. Pain and discomfort in primary dysmenorrhea is reduced by preemptive acupuncture or low frequency TENS. Eur J Rehab. In press.

41. Richardson PH, Vincent CA. Acupuncture for the treatment of pain: a review of evaluative research. Pain 1986; 24: 15-40.

42. Fox EJ, Melzack R Transcutaneous electrical stimulation and acupuncture: comparison of treatment for low-back pain. Pain 1976; 2: 141-148.

43. Haker E, Lundeberg T. Acupuncture treatment in epicondylalgia: A comparative study of two acupuncture techniques. The Clinical Journal of Pain 1990; 6: 221-226.

44. Thomas M, Lundeberg T. Importance of modes of acupuncture in the treatment of chronic nociceptive low back pain. Acta Anesthesiol Scand 1994; 38: 63-69. 
45. Levine JD, Gordon NC, Fields HL. The mechanism of placebo analgesia. Lancet 1978; 2: 654-657.

46. Chapman RC, Benedetti C. Analgesia following transcutaneous electrical stimulation and its partial reversal by a narcotic antagonist. Life Sci 1977; 21: 1645-1648.

47. Jernbeck J, Edner M, Dalsgaard C-J, Pernow B. The effect of calcitonin gene-related peptide (CGRP) on human forearm blood flow. Clinical Physiology 1990, 10, 335-343.

48. Collin E, Frechilla D, Pohl M, Bourgoin S, Le Bars D, Hamon M, Cesselin F Opioid control of the release of calcitonin gene-related peptide-like material from the rat spinal cord in vivo. Brain Research 1993; 609: 211-222.

Legend to figure 1: Box plot showing the number of hot flushes per week reported by 6 men with vasomotor symptoms due to castration therapy, before, during and after 10-12 weeks of acupuncture therapy.

Table 1: Baseline characteristics in seven men treated with acuuncture due to vasomotor symptoms after castration therapy.

$\begin{array}{lllll}\text { Code No } & \text { Age } & \text { Therapy } & \text { Months since start of therapy } & \text { No of flushes/week } \\ \text { 1SF } & 67 & \text { GnRHa } & 18 & 48 \\ \text { 2BR } & 65 & \text { GnRHa } & 8 & 36\end{array}$




$\begin{array}{lllll}3 \mathrm{BN} & 74 & \text { GnRHa } & 5 & 30 \\ \text { 4GB } & 76 & \text { GnRHa } & 3 & 86 \\ 5 \mathrm{OG} & 70 & \text { GnRHa } & 12 & 41 \\ 6 \mathrm{GK} & 79 & \text { GnRHa } & >12 & 89 \\ 7 \mathrm{GK} & 80 & \text { GnRHa } & 3 & 83\end{array}$

Bilaterally at:

UB/BL 15 Urinary bladder.

UB/BL 23 Urinary bladder*

UBBL 32 Urinary bladder*

Unilaterally at:

GV 20 Governor vessel

H/HT 7 Heart.

P/PC 6 Pericardium.

Liv/LR3 Liver.

SP 6 Spleen.

SP 9 Spleen.
Thoracic part of the back.

Lumbar part of the back

Lumbar part of the back

Top of the head.

Ulnar side of the wrist.

Volar side of distal forearm.

Dorsum pedis.

Lower leg, medial side.

Lower leg, medial side just below

the knee. 
Table 2: Acupuncture points and their anatomical position used for needle insertion. * denotes that these points were stimulated with $2 \mathrm{~Hz}$ in one group.

Table 3: Number of hot flushes per week in seven men treated with acupuncture due to vasomotor symptoms after castration therapy. Within parenthesis is the number of flushes in $\%$ of the number registered before start of therapy.

Code No Before th. After 2 w. After 6 w. After $10 \mathrm{w}$ After $24 \mathrm{w}$. Severity 1 $48 \quad 34$ 17 $12(25 \%) \quad 42(88 \%)$ less

2 36 20 9 $10(28 \%) \quad 23(56 \%)$ less

3 30 11 7 $8(27 \%) \quad 13(43 \%)$ less 4 86 109 $84 \quad 59(69 \%) \quad 47(55 \%)$ unchanged 


$\begin{array}{lllllll}5 * & 41 & 17 & 20 & 11(27 \%) & 23(56 \%) & \text { less } \\ 6 * * & 89 & 33 & 29 & 7(8 \%) & 4(4 \%) & \text { less } \\ 7 * * * & 83 & 122 & & & & \text { increased }\end{array}$

Average1-655.0 $\quad 37.3(68 \%) 27.7(50 \%) 17.8(32 \%) 25.3(46 \%)$

* Stopped therapy after 10 weeks because of low intensity of symptoms and long distance to travel to physiotherapist.

** Stopped therapy after 10 weeks because of a femoral neck fracture.

*** Stopped therapy after 3 weeks (five tretaments) because of back pain that made supine position during 30 minutes difficult. 